\title{
Três séculos, três Américas: irmandades épicas e imperativos hemisféricos
}

Charles Perrone

Universidade da Flórida

RESUMO: NAS AMÉRICAS, DEPOIS DE SUPERADO O MODELO ÉPICO CLÁSSICO, DESENVOLVERAM-SE NOVAS MODALIDADES DE POESIA ÉPICA PARA DAR CONTA DE REALIDADES EVOLUÍDAS. ESSE FENÔMENO LITERÁRIO SE ESTENDE DESDE MEADOS DO SÉCULO XIX ATÉ O SÉCULO XXI, EM VOZES UNIVERSALMENTE RESPEITADAS E EM VOZES MENOS CONHECIDAS. A POESIA NEO-ÉPICA TEM SIDO UMA DAS FORMAS DE A POESIA BRASILEIRA SE RELACIONAR COM SEUS CONGÊNERES NA AMÉRICA HISPÂNICA. AQUI SE EXAMINAM TRÊS EXEMPLOS DA NEO-ÉPICA DO BRASIL QUE SE PRETENDEM EXPRESSÃO NÃO SÓ DA NAÇÃO COMO TAMBÉM DO HEMISFÉRIO. O CONJUNTO DOS POEMAS TRAÇA UM ARCO GEOISTÓRICO, E DE CONSCIÊNCIA POÉTICA, DESDE OS TEMPOS IBÉRICOS MEDIEVAIS ATÉ OS DIAS ATUAIS, MARCADOS PELA TECNOLOGIA.

\begin{abstract}
IN THE AMERICAS, ONCE THE CLASSIC EPIC MODEL WAS SURPASSED, NEW MODALITIES OF EPIC APPEARED TO ACCOUNT FOR EVOLVED REALITIES IN THE HEMISPHERE. THIS LITERARY PHENOMENON EXTENDS FROM THE MID-NINETEENTH CENTURY TO THE TWENTY-FIRST, IN UNIVERSALLY RESPECTED AND LESS KNOWN VOICES. NEO-EPIC HAS BEEN ONE WAY FOR BRAZILIAN POETRY TO RELATE TO COUNTERPARTS IN SPANISH AMERICA. HERE, WE EXAMINE THREE EXAMPLES OF NEO-EPIC IN BRAZIL THAT EXPRESS BOTH THE NATION AND THE HEMISPHERE. THIS SET OF POEMS TRACES A GEO-HISTORICAL ARC, OF POETIC AWARENESS, FROM MEDIEVAL IBERIAN TIMES TO THE PRESENT DAYS, MARKED BY TECHNOLOGY.
\end{abstract}

PALAVRAS-CHAVE: ÉPICA - NEO-ÉPICA - ÉPICA LÍRICA - POÉTICA TRANSAMERICANA - RELAÇÕES HEMISFÉRICAS

KEY-WORDS: EPIC - NEO-EPIC - LYRICAL EPIC - TRANSAMERICAN POETICS - HEMISPHERIC RELATIONS 
uitas são as maneiras pelas quais quem faz, difunde e/ou critica a poesia brasileira tem tentado vencer a histórica separação de seus congêneres hispanoamericanos e mudar a face das inter-relações. Tais esforços compreendem peregrinação romântica, urbanidade modernista, provocações neovanguardistas, discursos insurgentes, invocações cantadas, ação coletiva, procuras pessoais, convites, viagens intercontinentais, eventos e sobretudo textos. Nas Américas, depois que o modelo épico clássico deixou de ser viável, escritores desenvolveram novas modalidades de poesia épica, ou quase-épica, para dar conta de realidades evoluídas no hemisfério. Esse fenômeno literário se estende desde meados do século XIX até o amanhecer do século XXI, tanto em vozes universalmente respeitadas quanto em vozes menos conhecidas. Além do sentido estritamente geográfico das três Américas (do Norte, Central, do Sul), a configuração tripartida pode entender-se conforme fatores culturais e lingüísticos dominantes - ibero-, anglo-, franco-americano - ou via origens, raça e etnias - indo-, euro-, afro-americano -, em molduras de organização que variam de nação para nação, região para região, área para área. Essas três formas de desenhar as Américas têm se manifestado em longas obras em verso, notadamente em um trio de trabalhos brasileiros inusitados que superam o enfoque nacional para favorecer perspectivas hemisféricas, tanto latino-americanas quanto todoinclusivas (oni-americanas), e que emergem respectivamente durante o último Romantismo, na década vanguardista do século XX, e na virada do XXI.

Convencionalmente, o que define a poesia épica, cantada ou escrita, é a narração em verso das façanhas de um herói que representa uma sociedade ou nação, seja na Antigüidade clássica, seja num período da história literária ocidental até o Romantismo. Ainda que a aventura heróica possa ter elementos fantásticos ou mesmo super-humanos, permanece essencial retratar a realização humana histórica. Tanto pela implementação de regras renascentistas quanto pela narrativa histórica, o melhor exemplo de épica na América hispânica é La araucana (1569-1589), de Alonso de Ercilla y Zúñiga. Na América ibérica, durante a marcha para a independência política que se conseguiu na primeira parte do século XIX, houve várias outras tentativas de criar épica, com resultados desiguais. $\mathrm{Na}$ América portuguesa colonial, o verso heróico se escreveu, inevitavelmente, na sombra de Os Lusíadas (1578), de Camões, a incisiva narração da nação e da exploração lusitanas. Os dois exemplos brasileiros mais citados - Caramuru de José de Santa Rita Durão (1781) e O Uraguai 
(1769), de Basílio da Gama - são pré-românticos. Depois da ascensão do romance, da independência das nações do Novo Mundo e da transição do neoclassicismo para a modernidade artística, os velhos modelos de épica herdados entram em colapso e cedem lugar a diferentes conceitos de poema longo. A instância mais poderosa nas Américas é a lírica-épica de Walt Whitman, Leaves of Grass (Folhas de relva), uma coleção multiforme em constante crescimento (1855-1881) composta de muitas enunciações líricas ligadas e uma história de vida democrática que se desenrola. Whitman reelabora o tecido episódico da épica tradicional e trata o plano objetivo com ênfase subjetiva, procurando uma obra fundacional para os Estados Unidos e olhando, ao mesmo tempo, para os vizinhos. Dele parte toda discussão de épica-lírica ou lírica-épica com teor americanista. Relações culturais transnacionais nas três Américas e dentro da América Latina são capitais na execução e na crítica das três obras ecumênicas aqui vistas. No período pré-republicano, a excepcional composição poética de Sousândrade, O guesa, desfez noções recebidas de ser "americano" e de fazer épica no Brasil. Durante o Modernismo de 1920 e 1930, a obra com qualidades épicas mais significativa foi Toda a América (1926), do poetadiplomata Ronald de Carvalho. No volumoso Latinomérica (2001), de Marcus Accioly, incorporam-se em um projeto expansivo a épica histórica, momentos destacados das letras hispano-americanas-brasileiras-estadunidenses, histórias da conquista e da resistência, e mais.

Obra única e desconcertante, O guesa compõe-se de treze cantos baseados tanto em fontes míticas quanto em histórias verdadeiras. ${ }^{1} \mathrm{O}$ périplo atravessa quase todas as partes da América do Sul, da Meso-América e das Antilhas, tendo momentos notáveis nos Estados Unidos. Refletindo tanto uma ética intensamente novo-mundista quanto um profundo envolvimento com a grande tradição da civilização ocidental (européia), O guesa é uma obra chamativa porquanto difere dos estilos literários dominantes da época, especialmente como praticados na América Latina, e pelas novidades que incorpora em um nível internacional. Usando-se as normas do Romantismo brasileiro - épica orientada para a construção da nação, indianismo celebratório, sen-

\footnotetext{
1 Primeira edição: O guesa errante (1876); segunda edição ampliada: O guesa (s/d, 188?). V. Frederick G. Williams e Jomar Moraes (orgs.), Poesia e prosa reunidas de Sousândrade (2003). Na segunda edição ampliada, quatro cantos estão incompletos ainda.
} 
timentalismo, subjetividade exagerada -, ficava muito difícil situar O guesa e os igualmente idiossincráticos volumes de lírica de Sousândrade. As ligações em O guesa são muitíssimas. O protagonista titular deriva de um mito dos índios muíscas da atual Colômbia; o autor tentou associá-lo, vítima que era de sacrifício ritual na lenda indígena, com povos representativos do século XIX, incluindo descendentes tribais. A glorificação de feitos "heróicos" e "nacionais" é uma característica básica da épica, e Sousândrade certamente queria glorificar seu protagonista polifacético, lugares diferentes e diversos grupos. Seus amplos objetivos abarcavam seu estado natal do Maranhão, o Brasil (o povo e o país, não o estado imperial, a que se opunha), o antigo império inca e as Américas como um todo. O guesa é inteiramente do Novo Mundo, apesar de ter alguns pulos na África e no sul da Europa para explorar aquilo que se enraizou de verdade depois da migração transatlântica. A narração começa nos Andes; é significativo que a viagem se inicie nas alturas, pois a localização física incorpora a admiração, a exaltação e uma posição elevada no sentido moral. Essa altitude prepara uma descida aos trópicos e, depois, uma hemisférica subida até a América do Norte. Essa série de cantos inclui lembranças ásperas da conquista, movimento pela Amazônia, estar em casa (Maranhão), a corte imperial (Rio de Janeiro), exploração de raízes (África, Ibéria, Mediterrâneo), as Antilhas, a América Central, o México, e uma estada ambivalente nos Estados Unidos, especialmente Manhattan, com uma celebrada exibição retórica no episódio "O Inferno de Wall Street". Depois de um contraste de elementos utópicos e desagradáveis ali, a narrativa se desloca para o Oceano Pacífico e o Panamá, entoando um hino às Américas e lembrando libertadores (Bolívar e outros) na Colômbia e na Venezuela, a civilização inca e o Cone Sul. ${ }^{2}$ A peregrinação é um mapa de preocupações artísticas e éticas.

Nesse imponente poema, Sousândrade joga com fidelidades estéticas e geoistóricas. O equilibrismo integra importantes bardos do Velho Mundo e, conseqüentemente, obras mestras, mas no fim das contas tais elementos ficam subordinados a horizontes humanos e naturais do Novo Mundo, desde tribos indígenas valentes conquistadas pela rapacidade ibérica até modelos políticos

2 Sobre aspectos de espaço e tempo, v. Claudio Daniel, "A poética sincrônica de Sousândrade". Zunái - revista de poesia \& debates. Disponível em: < http://www.revistazunai.com.br/index>. 
democráticos dos Estados Unidos e escritores transcendentalistas. ${ }^{3}$ Em O guesa, a intertextualidade canônica e a invocação de nomes surgem a cada passo. Há, continuamente, citações, alusões e elementos menores/maiores tomados ou adaptados da mitologia clássica e da épica, da Bíblia, de Dante, de Camões, etc. Apesar de características compartilhadas com Paradise Lost, por exemplo, Sousândrade se preocupa sobretudo com a aceitação política e ideológica de povos sul-americanos. ${ }^{4}$ Essas muitas vozes incluem subalternos e comunidades dominadas do passado colonial. A visão social que Sousândrade constrói por meio de seu herói também bebe de fontes antigas e correntes. Ele implica um modelo para uma organização humana ideal, associado utopicamente com a sociedade comunitária dos incas, ao lado de conceitos gregos, da república de Platão e até mesmo raízes do cristianismo livremente interpretadas. Os Estados Unidos democráticos, eventualmente, ofereciam muito para se admirar, ainda que formas de opressão, corrupção e colonialismo merecessem sátira e escárnio lírico.

O guesa revela um americanismo fundamental em paratextos e versos. Havendo citado Homero e reconhecido outras colunas literárias em seu prefácio, o autor frisa seu próprio hemisfério e a inevitável novidade de expressão deste lado do Atlântico. ${ }^{5}$ Os cantos de $O$ guesa se orientam por atitudes que honram uma arte seleta de ascendência européia enquanto afirmam o caráter superior e o potencial do Novo Mundo. Pairam um sentimento hemisférico e um respeito simpático pelos povos dominados por conquistadores, e fica uma sensação de melhoramento cultural no Novo Mundo. O herói leva um profundo interesse pela terra e pelos povos das Américas ao colosso do Norte. Sousândrade via nos Estados Unidos um potencial ideal e utópico para o desenvolvimento e a democracia. Perto do fim do interlúdio infernal, a vOz poética, como que desterritorializando de modo bem créole, até se compara a Colombo, cujo nome virou sinônimo da época do Novo Mundo.

Do ponto de vista da poética transamericana, urge realçar as ligações hispânicas em $O$ guesa. O primeiro historiador sério da literatura brasileira, Sílvio Romero, não conferia posição tão alta a Sousândrade, mas fez questão de declarar que ele era o "único de nossos poetas" a se preocupar com um as-

\footnotetext{
3 Cláudio Cuccagna (A visão do ameríndio na obra de Sousândrade) explora os pólos principais do poema - americano/europeu, colonizado/colonizador, republicano/monarquista.

4 V. Luiza Lobo, Tradição e ruptura: O guesa de Sousândrade e Épica e modernidade em Sousândrade.

5 V. Augusto e Haroldo de Campos, Revisão de Sousândrade.
} 
sunto americano fora do Brasil, algo tomado das repúblicas hispânicas. ${ }^{6}$ Esse fato não escapou à atenção do célebre escritor peruano Ricardo Palma, que escolheu La araucana, Tabaré (Juan Zorrilla de San Martín, Uruguai, 1886) e O guesa como os poemas que satisfaziam mais completamente o ideal do americanismo literário. O ente épico de Sousândrade (com herói, mito, geografia e história) cita tanto chefes nativos quanto Colombo, e se estende sobre o hemisfério desde Niágara até a Terra do Fogo, numa profunda ligação geocultural que lembra outras realizações poéticas. Claudio Daniel opina que o final de "O Inferno de Wall Street" antecipa a dissolução da linguagem em Altazor, do poeta chileno Vicente Huidobro. Por sua vez, Haroldo de Campos ficou impressionado com as implicações lingüísticas de O guesa, cujo escopo só teria termos de comparação, quase meio século depois, na mais majestosa das neoépicas da América Latina, Canto geral (1950), de Pablo Neruda. ${ }^{7}$

O espanhol foi um dos doze idiomas que Sousândrade empregou em sua neo-épica multilíngüe, a qual ligava literatura clássica (grego, latim), sabedoria indígena (tupi, quíchua, etc.) e outras línguas coloniais (inglês, francês). O lado lingüístico gregário espelha uma ética abarcadora e uma estética pannacional que se encontrou integralmente no português brasileiro. O idioma de Sousândrade transformou-se em uma estrutura errante que absorvia sons, nomes, vocábulos e idéias à medida que se movia pelas Américas, em séculos anteriores em reinos poéticos, e no século XIX na história real. Para o crítico argentino-brasileiro Jorge Schwartz, O guesa incorpora "um verdadeiro cosmo-pan-americanismo"; ele compara Sousândrade, Baudelaire e Whitman como avatares contemporâneos de poética cosmopolita. ${ }^{8}$ Mais que qualquer conterrâneo, Sousândrade imaginava o país como sendo uma ligação contínua com os vizinhos da América Latina. Mediante parâmetros comparativos e comparatistas, O guesa, a textualização de um poeta-herói que emerge de um périplo singular concebido na multiplicidade e na cumplicidade, transita numa dimensão hemisférica, a mais perto de casa.

Toda a América constitui a mais americana e americanista das obras do Modernismo brasileiro. Tem sido sempre comparada à de Walt Whitman, e a

\footnotetext{
Cf. Sílvio Romero, História da literatura brasileira, p. 79.

7 Haroldo de Campos, "A peregrinação transamericana do Guesa de Sousândrade". Revista USP n. 50 (2001), p. 221-231. Originalmente nos Cuadernos hispanoamericanos n. 78 (2000), p. 70-76.

8 Cf. Jorge Schwartz, Vanguarda e cosmopolitismo, p. 7-13, 9.
} 
abordagem do brasileiro, hemisférica e/ou continental, bem pode ser qualificada de pan-, inter-, trans-, ou mesmo de oni-americana. Embora ampla em termos espaço-temporais, Toda a América não é propriamente um poema épico, pois não tem herói, viagem sustentada, ou fluxo narrativo. ${ }^{9}$ É um tipo especial de poema épico-lírico, uma seqüência geocultural organizada por meio do olhar do falante. O sumário já revela uma perspectiva bem ampla; há um prefácio meio declamatório; um poema comprido acerca do Brasil; nove poemas sobre as Antilhas, a América do Norte e a América do Sul de língua espanhola; nove epigramas sobre o México; e cinco variações sobre "Toda a América" (I-V). Estes últimos poemas, apelando com freqüência de modo metaliterário, confirmam, solidificam e enriquecem elementos essenciais que subtendem as instâncias líricas precedentes. Há evidentes falhas no mapeamento dos três continentes, mas os cinco poemas finais, dadas sua amplitude e sua intensidade, poderiam ser considerados compensatórios. A continuidade do texto dá-se na estabilidade de traços no falante, que percebe uma diferença entre o raciocínio europeu e a sensibilidade americana. Tal contraste aparece bastante nos poemas a seguir, que amiúde têm a intenção de justapor o europeu e o americano, o Velho Mundo e o Novo Mundo; e esse hemisfério abarca a liberdade e uma felicidade singular. O livro foi até tomado como algo quase partidário, como uma mostra de "um compromisso com o americanismo, um desejo inocente de mostrar a superioridade do Novo Mundo e o entusiasmo pelo futuro." 10 Toda a América é claramente um esforço textual para combater o isolamento e a auto-absorção. A tradução para a Espanha poderia ter sido distribuída no exterior; no prólogo, sobre Carvalho se diz "de nuestra America [...] un poeta integralmente representativo". ${ }^{11} \mathrm{Em}$ "The Great Song of America", opina-se que Neruda teria sentido o impacto de Toda a América. ${ }^{12}$

Há poemas na coletânea que, tomados isoladamente, podem fazer pensar em fantasia romântica, essencialização ou viés turístico. Porém, celebrações

\footnotetext{
9 Ronald de Carvalho, ed. facs. Toda a América (2001[1926]). Dado o reduzido espaço aqui, remeto, para mais considerações, a meu artigo "A poética da criação novo-mundista em Toda a América". ArtCultura, Uberlândia - UFMG, 8.12, p. 117-129, 2006.

10 Júlio Carvalho, "Ronald de Carvalho", in Poetas do modernismo (Brasília: INL, 1972), pp. 223-278.

11 Francisco Villaespesa, trad. e prólogo a Ronald de Carvalho, Toda la America (1935), p. 7. Seguida do original brasileiro, i. e., edição bilíngüe.

12 Gordon Brotherston, Latin American Poetry: Origins and Presence, p. 84.
} 
de cor ou festividade e coisas do gênero não dominam as centenas de páginas de movimento poético através das Américas. Ao contrário, Carvalho questiona aquilo que está dado e acaba confrontando clichês em seu americanismo. Com um olhar simpático, mas ao mesmo tempo acurado, deseja afirmar uma instância americanista. Seus versos mapeiam sem preconceito lugares emergentes, honrando tanto o passado indígena quanto o ibérico e mantendo-se abertos à pluralidade. Certos autores ibero-americanos dos anos 20 questionaram a tendência de representar o Novo Mundo como maravilhosamente novo, telúrico, ou essencialmente orgânico (no sentido de unificado). Em Toda a América, Carvalho tenta superar a simples afirmação de localidade e problematizar a América, engrandecendo-a. As cinco variações de "Toda a América" oferecem os melhores exemplos de consciência amplificada. O toque final de I entrelaça o poeta (ser especial, dotado) e a América (local de descobertas seculares, invenção, lirismo artificial e empreendimento criativo). Em poemas que veiculam "o milagre da criação", vê-se uma América nativa mas totalmente em processo, uma obra em andamento, de imigração e genialidade humana. A última palavra (criação) conota o ato de fazer existir e um fazer humano especialmente artístico. Nas línguas ibéricas, existem, para ajudar a vender a seqüência poética, significados adicionais, tais como cultivo (colheita), procriação (animais) e amamentação (infantes). Compõe-se um modo superior de cognição estética que distingue certos trabalhos de vanguarda de outros.

Em Latinomérica, Accioly reconhece tanto Toda a América quanto O guesa. $\mathrm{O}$ autor se ocupa com legados literários, mormente no contexto do colonialismo e do neocolonialismo, atendo-se a um ideal de escrita comprometida, à idéia de que a poesia deveria dirigir-se a heranças e estruturas de opressão. Sua obra neomilenária é uma rica fonte poética para contemplar a trajetória da épica, a poesia da América Latina (como um todo) e a imaginação hemisférica. Latinomérica é uma épica para o terceiro milênio, um ambicioso atlas cultural e poético, e uma das mais amplas obras em verso na história das letras latino-americanas. Há vinte cantos de texto principal e paratextos pesados, incluindo 25 epígrafes de diversas proveniências, um comprido sumário e um longuíssimo apêndice (45 páginas) de auto-explanação sob a rubrica de "Portulanos" (cartas medievais de navegação), que conota a expansividade e a complexidade do poema em si. O título geral sugere a amplidão geoistórica, chamando a atenção para si por meio da alteração do nome (espanhol) 
Latinoamérica com a fusão com o nome Homero, o mais venerável dos nomes na tradição épica ocidental. Como se explica no posfácio, o título contraído alude a Omeros, uma epopéia moderna celebrada. A principal preocupação fica com relações coloniais e neocoloniais num contexto maior do hemisfério ocidental, onde Estados Unidos - América do Norte e América Latina são as grandes figuras.

Uma sensação de inversão e de conflito norte-sul imbui-se no longo poema de Accioly, de modo a qualificá-lo como outro caso da "justiça poética" que Bernucci identifica na moderna épica latino-americana, texto grandioso com ira histórica subjacente, profunda insatisfação baseada em acontecimentos injustos, e um imperativo de protesto presente acerca de versões oficiais de eventos. ${ }^{13}$ Algumas chaves para se entender Latinomérica são a organização, o layout e o desenrolar da narração. A motivação geral da obra é a procura da identidade. Os milhares de versos - principalmente na oitava rima usada, entre outros, por Camões em Os Lusíadas, mas também com algumas variações métricas, em formas eruditas e populares - representam a luta para dar conta da conquista, da dispersão lingüística e cultural, de séculos de opressão, da tirania e das relações desiguais. Quinhentos anos de história do Novo Mundo, sobretudo da América Latina, complementados por mitos pré-colombianos, são objeto de comentário que tem a liberdade de errar cronologicamente dos Quinhentos aos Oitocentos e no final dos Novecentos.

Aqui, como em O guesa, uma forte atitude americanista nunca implica subestimar o legado literário ocidental até a Grécia antiga. Há um contraste produtivo de letras do Velho Mundo e repertórios do Novo Mundo. Accioly começa com misturas de tambores tribais e musas, mais invocações pagãs e cristãs simultâneas. A intertextualidade em Latinomérica é fundamental. Mediante homenagens condensadas ou citações de autores e títulos, esse compêndio engloba tudo, desde mitos de criação indígenas e épica latinoamericana a badalados músicos contemporâneos do Brasil (Jobim, Buarque e outros) e da América Hispânica (Piazzolla, Parra, Jara). A concatenação de artistas implica uma integração ideal em uma só grande canção das Américas.

13 Cf. Leopoldo M. Bernucci, "Justiça poética na épica latino-americana moderna", Revista USP n. 50 (2001), p. 238-246. V. sobre Accioly e a épica nacional, Anazildo Vasconcelos da Silva e Christina Ramalho, História da epopéía brasileira: teoria crítica e percurso, vol. 3 (Rio de Janeiro: Garamond, no prelo). 
Os mais abundantes são nomes canônicos da poesia e da ficção de todas as Américas. O elo mais forte é com Canto geral, uma tentativa de cantar toda a realidade da América Latina e de poetizar uma cosmovisão socialista.

Latinomérica se compunha quando as Américas se aproximavam do quinto centenário da chegada de Colombo no Novo Mundo. O último canto se completou depois daquela observância, enquanto o Brasil antecipava seu próprio aniversário de 500 anos, como o poeta-falante esclarece, não na prosa do apêndice, mas no verso do penúltimo poema (1996). O ano citado está a meio caminho entre o quinto centenário de Colombo (1992) e o de Cabral (2000), situando o autor numa espécie de equilíbrio cronológico para contemplar e ter contemplado sua nação e a região como um todo. As explicações dos Portulanos terminam (assinados 2000) com referência a navigare necesse est, vivere non est necesse, frase antiga feita famosa por Pessoa e Caetano, a qual é contraposta a declarações sobre a poesia de Hölderlin e Cortázar, desse modo mantendo tanto um ponto de vista latino-americano quanto conexões com o cânone da literatura européia, a qual nunca se rejeita como tal na afirmação de ser americano. Latinomérica é ainda uma obra recente; sua recepção crítica está in progress, mas certamente a épica de Accioly tem mais conteúdo americano que qualquer outra obra da literatura brasileira desde 1500.

Em construtos literários neo-épicos, espaços poéticos inventados, arenas estilísticas, jornadas continentais da vida real e expedições por internet, a viagem é um aspecto essencial da poética transamericana e do intercâmbio transatlântico. Como se verifica em O guesa, em Toda a América e em Latinomérica, expor-se a Outros no hemisfério e se engajar com os discursos de línguas irmãs são atos invariavelmente produtivos. Aberturas para alianças e futuros.

\section{Referências Bibliográficas}

ACCIOLY, Marcus. Latinomérica. Rio de Janeiro: Topbooks/Biblioteca Nacional, 2001.

BROTHERSTON, Gordon. Latin American Poetry: Origins and Presence. Cambridge: University Press, 1975.

CAMPOS, Augusto de; CAMPOS, Haroldo de. Revisão de Sousândrade. 3. ed. São Paulo: Perspectiva, 2002 [1964]. 
CARVALHO, Ronald de. ed. facs. Toda a América. Rio de Janeiro: Rádio Cultural, 2001 [1926].

CUCCAGNA, Cláudio. A visão do ameríndio na obra de Sousândrade. São Paulo: Hucitec, 2004.

LOBO, Luiza. Tradição e ruptura: O guesa de Sousândrade. São Luís: SIOGE, 1979. . Épica e modernidade em Sousândrade. Rio de Janeiro: EDUSP/Presença, 1986.

PERRONE, Charles A. A poética da criação novo-mundista em Toda a América. ArtCultura, Uberlândia, UFMG, 8.12, p. 117-129, 2006.

ROMERO, Sílvio. História da literatura brasileira. Rio de Janeiro: José Olympio, 1943? [1888/1903]. p. 79.

SCHWARTZ, Jorge. Vanguarda e cosmopolitismo. São Paulo: Perspectiva, 1983.

VILLAESPESA, Francisco. Trad. e prólogo a CARVALHO, Ronald de. Toda la America. São Paulo/Rio de Janeiro: Editora Hispano-Brasileira, 1935.

WALCOTT, Derek. Omeros. New York: Farrar, Strauss and Giroux, 1990.

WILLIAMS, Frederick G.; MORAES, Jomar. (Orgs.) Poesia e prosa reunidas de Sousândrade. São Luís: AML, 2003. 